\title{
Unusual MR Imaging Features in CT Hyperdense Posterior Fossa Dermoids: Report of Two Cases
}

\author{
Anbazhagan Sathiaprabhu ${ }^{1} \quad$ Nichanametla Sravani $^{2} \quad$ Krishnan Nagarajan $^{2} \quad$ Sekar Sabarish $^{2} \quad$ Kapil Patil $^{1}$ \\ ${ }^{1}$ Department of Neurosurgery, Jawaharlal Institute of Postgraduate \\ Medical Education \& Research (JIPMER), Pondicherry, India \\ ${ }^{2}$ Department of Radio-Diagnosis, Jawaharlal Institute of Postgraduate \\ Medical Education \& Research (JIPMER), Pondicherry, India

\begin{abstract}
Address for correspondence Krishnan Nagarajan, MD, DM, Department of Radio-Diagnosis, Jawaharlal Institute of Postgraduate Medical Education \& Research (JIPMER), Pondicherry 605006, India (e-mail: Iknagarajan1@gmail.com).
\end{abstract}

Indian J Neurosurg 2019;8:63-66
Abstract
Keywords
- posterior fossa dermoid
- hyperdense dermoid
- magnetic resonance imaging

Dermoids, either intracranial or in the rest of the body, usually have typical imaging findings due to their fat contents as fat density in computed tomography (CT) and T1- and T2-hyperintensity in magnetic resonance imaging (MRI). Variable imaging appearances have been described due to soft tissue contents, hair, calcification, or even tooth. Posterior fossa dermoids have been reported as a specific variant that shows hyperdensity in CT and mixed signal intensity in MRI. We report two cases of posterior fossa CT hyperdense dermoids that showed unusual MRI features in the form of signal loss in magnetization transfer images and lipid peak in magnetic resonance spectroscopy. Both patients underwent surgical resection and histopathological confirmation and the causes of this unusual imaging appearance are discussed.

\section{Introduction}

Dermoids are congenital ectodermal inclusion cysts and uncommon lesions forming less than $1 \%$ of intracranial tumors. But due to their virtually pathognomonic and classical imaging appearances, diagnosis is usually straightforward. Variations such as computed tomography (CT) hyperdensity and MR T1 hyperintensity owing to the presence of high proteinaceous content, have been rarely reported with dermoids., ${ }^{1,2}$ CT hyperdense dermoids have been reported in the posterior fossa but the cause of this atypical appearance is still not clear, though varied reasons like high protein content or hemorrhage have been ascribed to this appearance. ${ }^{3-17}$ It is pertinent to know about unusual imaging characteristics of dermoid cysts because they may be confused with other more common lesions of the posterior fossa like meningioma, hemangioblastoma, or even as hemorrhage and the basis of their appearances. Presence of unusual features such as mural nodule without any dermal sinus tract may add to further diagnostic uncertainty.

\section{Case 1}

A 26-year-old male patient presented with complaints of headache and ataxia for 6 months along with sudden onset vomiting and altered sensorium. CT showed a well-defined hyperdense lesion in midline posterior fossa with an irregular calcific focus along the anterior wall and small areas of hypodensity with fat attenuation. Posterior occipital bone in relation to the lesion showed mild thinning due to remodeling. The lesion is seen effacing the fourth ventricle causing obstructive hydrocephalus. Patient underwent emergency V-P shunt. Magnetic resonance imaging (MRI) brain revealed $\mathrm{T} 1$ hyperintense and T2/fluid-attenuated inversion recovery (FLAIR) hypointense mass in the posterior fossa extending from the torcula up to the inferior vermis/uvula across the foramen magnum causing effacement of fourth ventricle and compressing the cervico-medullary junction. The lesion showed signal loss in $\mathrm{T} 2$ with fat saturation sequence. The mural nodule showed T1 hypo to isointense and T2 hyperintense signal intensities ( - Fig. 1). Serpiginous T2 hypointensity is noted arising from the wall which was later found to be due to hair follicles. VP shunt was noted in situ with bilateral small subdural collections postshunting. Patient was taken up for elective decompression through midline suboccipital craniectomy. Cystic lesion was noted surfacing between the bilateral tonsils of inferior vermis. The lesion was excised with mural nodule, calcifications, and hair follicles and the semisolid contents showed chocolate-brown discoloration and cholesterol crystals. The gray-white and brown bits of tissue were sent to histopathological examination which
DOI https://doi.org/

10.1055/s-0039-3402594

ISSN 2277-954X.
(C2020 Neurological Surgeons'

Society of India
License terms

()(1) $\Theta \circledast$ 


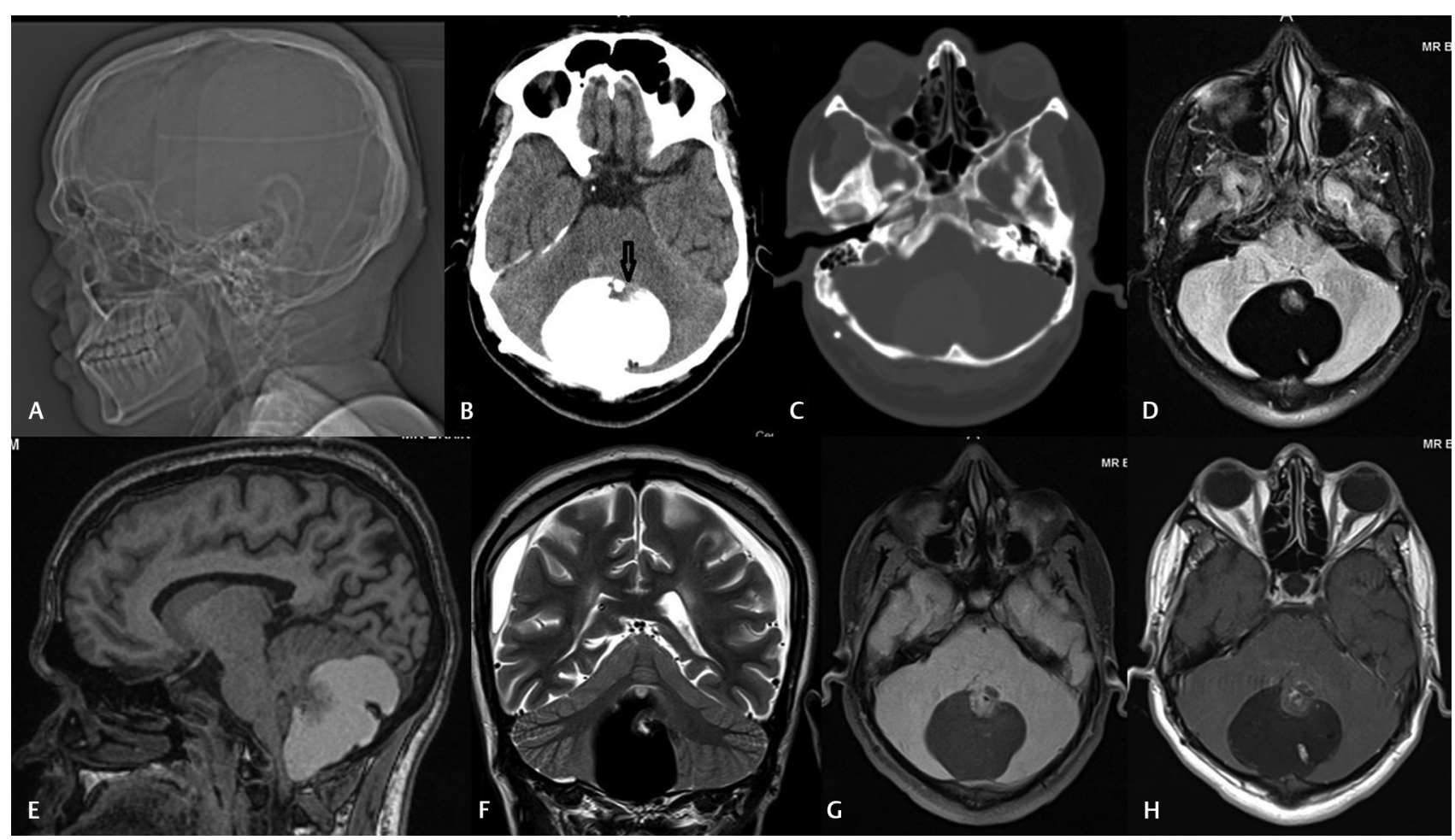

Fig. 1 First patient. CT scout (A), axial images brain (B), and bone (C) window showing hyperdense posterior midline mass lesion with anterior isodense mural nodule (arrow in B). Mild occipital vault indentation is noted without erosion. Magnetic resonance imaging (MRI) FLAIR axial (D), T1 sagittal (E), T2 coronal (F), T1 with fat saturation (G), and postcontrast T1 with magnetization transfer (MT) (H) showing FLAIR/T2 hypointense $\mathrm{T} 1$ hyperintense lesion with signal loss in fat saturation and MT. CT, computed tomography; FLAIR, fluid-attenuated inversion recovery.

confirmed the diagnosis of dermoid cyst. Postoperative CT showed near-complete excision without any residue.

\section{Case 2}

A37-year-old male patient presented with headache on-and-off for the past 18 months. Plain CT showed hyperdense posterior fossa mass in the midline and left side posteriorly with a small posteromedial calcific speck and mild scalloping of inner table of occipital bone on the left side. He also underwent emergency V-P shunt. MRI showed T1 hyperintense T2/FLAIR hypointense lesion in the posterior fossa with a more $\mathrm{T} 1$ hyperintense mural nodule. The lesion showed signal loss in $\mathrm{T}^{*}$ gradient-echo (GRE) sequence, diffusion-weighted imaging (DWI), and heavily T2-weighted SPACE (sampling perfection with application optimized contrast using different flip-angle Evolutions) sequences with susceptibility-artifacts in the apparent diffusion coefficient (ADC) images of DWI. No enhancement was noted with gadolinium. Postcontrast magnetization transfer (MT) T1 image showed no enhancement but relative signal loss probably due to fat saturation. Proton magnetic resonance spectroscopy ( ${ }^{1} \mathrm{H}$ MRS, two-dimensional chemical shift imaging [CSI], Echo time TE of 30 milliseconds) showed large lipid peak at 1.0 to $2.0 \mathrm{ppm}$ resonances ( $\boldsymbol{- F i g}$. 2). The operative findings were similar with chocolate brown cystic contents with mural nodule, but there were no obvious hair follicles. But histopathological specimen showed tissue fragment with tiny hair shafts. Sections show cholesterol clefts and foci of necrosis admixed with tiny cysts lined by pseudostratified columnar epithelium along with hair follicles confirming the diagnosis of dermoid. The cyst fluid was acellular with calcific debris. The MRI done after 2 months after surgery revealed operative site collection without any residual dermoid or enhancement.

\section{Discussion}

The first report of dense dermoid was in 1983 by Cecchini et al in the craniocervical region along with six similar cases. ${ }^{3}$ Another similar craniocervical lesion by Romero et al in 1987 was reported as colloid cyst. ${ }^{4}$ Mamata et $\mathrm{al}^{9}$ reported a mixed density parasellar dermoid with areas of hyperdensity and a speck of fat. They found that cholesterol mixture rather than the hemorrhagic component, seen in histopathology as the reason for the appearance. They hypothesized that partial arachnoid adherence of the lesion with minor rupture could have resulted in inflammatory response and intratumoral hemorrhage. Brown et $\mathrm{al}^{10}$ in their report of dermoid with mural nodule who underwent CT and MR imaging referred to seven cases reported in literature. They associated this unusual imaging appearance to a combination of "saponification of lipid or keratinized debris and secondary microcalcifications in suspension, partially liquefied cholesterol, high protein content, and hemosiderin or iron-calcium complexes relating to previous hemorrhage." Li et al ${ }^{14}$ first used the term "CT hyperattenuating dermoid cyst" and mentioned about nine cases in literature till then and reported another dense dermoid lesion 


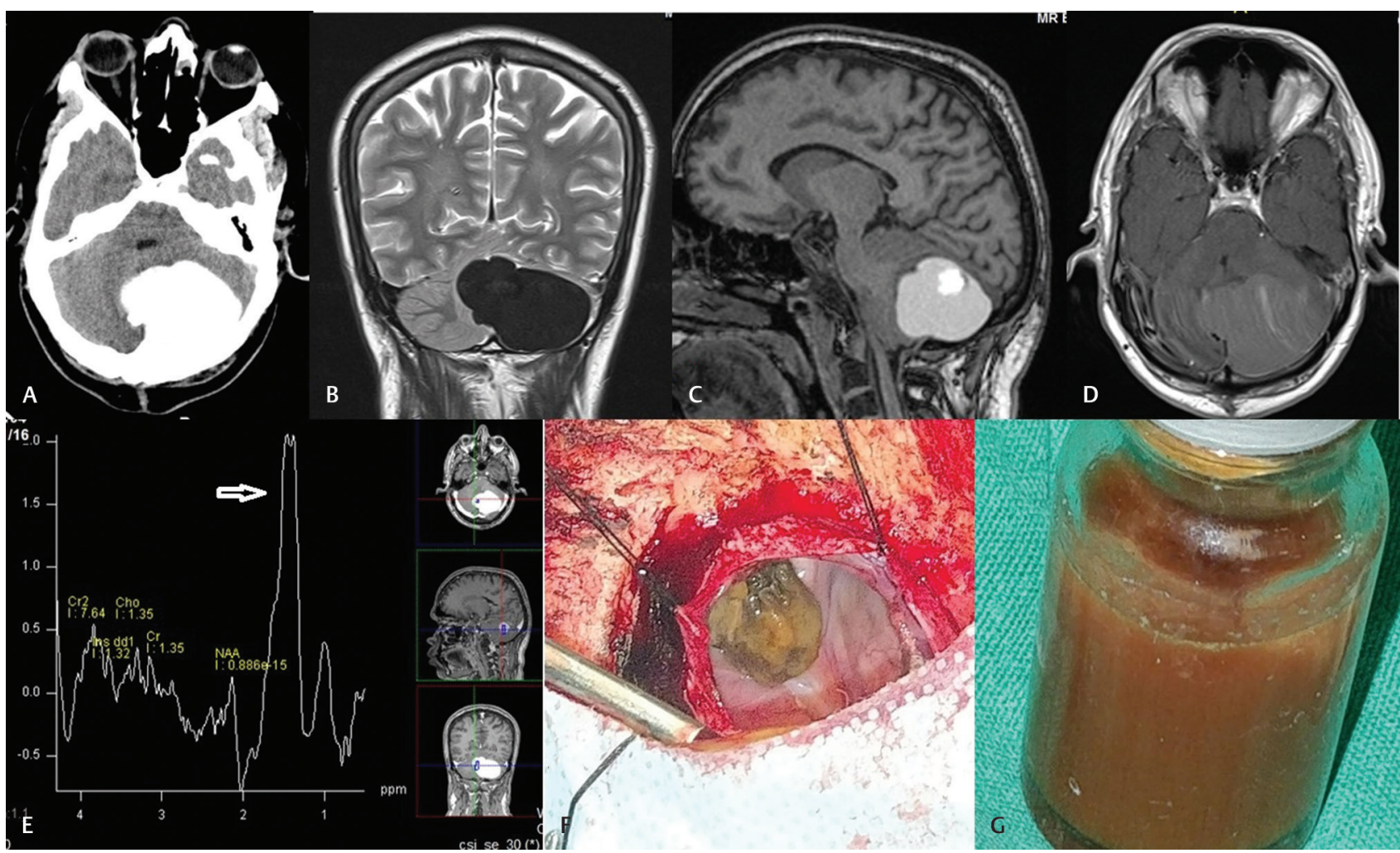

Fig. 2 Second patient. CT axial (A), MRI T2 coronal (B), T1 sagittal (C), postcontrast T1 with MT (D), and MRS (E) showing similar signal intensity lesion with large lipid peak in MRS at $0.9-1.8$ ppm position (arrow). Intraoperative photography (F) showing grayish brown mural nodule after aspiration of the cyst contents $(\mathbf{G})$ which was thick chocolate-brown fluid. CT, computed tomography; MRI, magnetic resonance imaging; MRS, magnetic resonance spectrography.

with mural nodule and ascribed it to high protein and calcium content. Luan et a ${ }^{15}$ reported dense dermoid and correlated the appearance of partially calcified wall, keratinous component, and old hemorrhage for the imaging features and mentioned trauma as a factor in their appearance. But trauma as a cause of this appearance is unlikely and our resected specimen did not show any brown or altered discoloration of old hemorrhage and the gross appearance was somewhat similar to what is seen in craniopharyngiomas. Another interesting finding seen in two patients was the signal loss or suppression of $\mathrm{T} 1$ hyperintensity when MT was used in postcontrast T1 study. The lesions did not show any enhancement, but there was signal loss due to MT. In MT, proteins and lipids are known to have different effects and this may be a reason for this finding. ${ }^{18,19}$ One of our cases also showed large lipid-lactate resonance in ${ }^{1} \mathrm{H}$ MRS at 0.9 to $1.3 \mathrm{ppm}$ position indicating the lipid nature of the lesion. The contents are not that of mesenchymal fatty tissue as seen in lipomas but complex mixture of cholesterol and protein, similar to the "machine oil"-like contents of craniopharyngiomas.

\section{Conflict of Interest}

None declared.

\section{References}

1 Orakcioglu B, Halatsch ME, Fortunati M, Unterberg A, Yonekawa Y. Intracranial dermoid cysts: variations of radiological and clinical features. Acta Neurochir (Wien) 2008;150(12):1227-1234, discussion 1234
2 Canbaz B, Kemerdere R, Ocal E, Tanriverdi T. Intracranial dermoid cyst mimicking a giant thrombosed aneurysm. Neurol India 2004;52(4):524-525

3 Cecchini A, Pezzotta S, Paoletti P, Rognone F. Dense dermoids in craniocervical region. J Comput Assist Tomogr 1983;7(3):479-483

4 Romero FJ, Ortega A, Ibarra B, Pomés J, Rovira M. Craniocervical neuroepithelial cyst (colloid cyst). Am J Neuroradiol 1987;8(6):1001-1002

5 Dănăilă L, Carp N. Dermoid tumour of the fourth ventricle with hyperdense aspect demonstrated on CT scan. Case report. Neurol Psychiatr (Bucur) 1989;27(3):231-236

6 Drolshagen LF, Standefer M. Dense dermoid cyst of the posterior fossa. Am J Neuroradiol 1991;12(2):317

7 Bizzozero L, Talamonti G, D’Angelo VA, Casadei GP, Arrigoni GL, Collice M. Dermoid cyst mimicking hematoma in the posterior fossa. Clin Neurol Neurosurg 1992;94(1):61-63

8 Goh GJ, Page RD, Nixon TE. An unusual CT and MR appearance of a posterior fossa dermoid. Eur J Radiol 1995;20(1):46-47

9 Mamata H, Matsumae M, Yanagimachi N, Matsuyama S, Takamiya Y, Tsugane R. Parasellar dermoid tumor with intra-tumoral hemorrhage. Eur Radiol 1998;8(9):1594-1597

10 Brown JY, Morokoff AP, Mitchell PJ, Gonzales MF. Unusual imaging appearance of an intracranial dermoid cyst. Am J Neuroradiol 2001;22(10):1970-1972

11 Neugroschl C, David P, Sadeghi N, et al. Unusual CT features of dermoid cyst in the posterior fossa. Eur Radiol 2002;12(11):2726-2729

12 Tada Y, Kannuki S, Kuwayama K, Kouyama Y. Atypical presentation of a dermoid cyst with porencephaly [in Japanese]. No Shinkei Geka 2003;31(11):1215-1220

13 Sanchez-Mejia RO, Limbo M, Tihan T, Galvez MG, Woodward MV, Gupta N. Intracranial dermoid cyst mimicking 
hemorrhage. Case report and review of the literature. J Neurosurg 2006;105(4, Suppl):311-314

14 Li ZJ, Miao YX, Sun P, et al. Unusual CT hyperattenuating dermoid cyst of cerebellum: a new case report and literature review. Cerebellum 2011;10(3):536-539

15 Luan Y, Wang H, Zhong Y, Bian X, Luo Y, Ge P. Traumatic hemorrhage within a cerebellar dermoid cyst. Int J Med Sci 2012;9(1):11-13

16 Wang X, Yu Y, Zhang X, et al. Unusual imaging appearance of a huge intracranial dermoid cyst located across the anterior and middle skull base. J Neurol Surg A Cent Eur Neurosurg 2013;74(Suppl 1) :e185-e187
17 Tan LA, Kasliwal MK, Harbhajanka A, Kellogg RG, Arvanitis LD, Munoz LF. Hyperdense suprasellar mass: an unusual radiological presentation of intracranial dermoid cyst. J Clin Neurosci 2015;22(7):1208-1210

18 Morina A, Kelmendi F, Morina Q, Morina D. Cerebellar dermoid cyst with contrast enhancement mural nodule: case report. Acta Clin Croat 2014;53(4):479-482

19 van Buchem MA. Magnetization transfer: applications in neuroradiology. J Comput Assist Tomogr 1999;23(Suppl 1):S9-S18 